\title{
Immigrant influx and social cohesion erosion
}

Florence Neymotin

\author{
Correspondence: \\ fneymotin@nova.edu \\ H. Wayne Huizenga School of \\ Business and Entrepreneurship, \\ Nova Southeastern University, 3301 \\ College Avenue, Fort Lauderdale, FL \\ 33314, USA
}

\begin{abstract}
If immigration causes a decrease in social cohesion, then it may also be an important contributing factor in the recent failure of financial institutions. The present analysis finds some evidence for a negative relationship between immigration and volunteering from the Current Population Survey 2004-2008 September Supplements. Various specifications confirm the tendency of immigrant inflows to decrease social cohesion, as measured by the tendency of native U.S. citizens to volunteer. Differences in effect by type of volunteering organization, country of origin of immigrants, functional form, and voting as the relevant measure of social cohesion are explored with similar patterns of results. Differences in effect by city size provide a counterpoint, lending support to the alternative idea that immigration does not in fact decrease social cohesion.

JEL codes: H8; Z13; 161

Keywords: Social cohesion; Volunteering; Immigration
\end{abstract}

Social cohesion, the commitment on the part of members of a group towards perceived common goals, is clearly a prerequisite for the flourishing of that group. Cohesion is promoted by feelings of group unity and pride, while the erosion of social cohesion has been considered as a possible contributing factor in our current worldwide bleak economic state. A decrease in social cohesion leads to weaker civic participation, as well as reduced public good provision, and it may also lead to the disruption of financial institutions through weakened property rights, reduced micro-credit lending, higher rates of default and decreased viability of small firms.

Groups that are difficult to join, contain similar members, promote a shared sense of community, and highlight differences with "out-group" individuals usually possess greater social cohesion. Conversely, Putnam (2007) theorized that the disruption of social cohesion has been heightened by immigration. Unfortunately, it is often difficult to test the veracity of this claim in a causal sense using large, recent, representative and disaggregated data. Scholars subsequent to Putnam's 2007 study have found inconsistent results for the United States-the focus of most of this research-as opposed to results in Europe. Data from European countries (as opposed to the United States) show that the relationship between social cohesion and measures of diversity and immigration are generally mitigated when including measures of income inequality (Becares 2011; Demireva 2011; Gesthuizen et al 2009). This result has arisen in a number of European studies, including, for example, studies of the UK using Census and Citizenship Survey data (Becares 2011), and studies of twenty-eight separate European countries in Gesthuizen et al. (2009).

(c) 2014 Neymotin; licensee Springer. This is an Open Access article distributed under the terms of the Creative Commons Attribution License (http://creativecommons.org/licenses/by/2.0), which permits unrestricted use, distribution, and reproduction in any medium, provided the original work is properly credited. 
The effect of immigration on natives in particular, as well as after disaggregation by ethnic/country of origin groups and type of volunteering has also rarely been attempted, although the inclusion of all of these elements would lead to a much clearer picture of how immigration is truly affecting social cohesion in the United States. More specifically, determining the spillover from immigrants to natives would help disentangle the effect of immigrants on lowering social cohesion simply by a local average effect from immigrant interaction with natives and, in the language of Alesina, an "aversion to heterogeneity" effect. It is for this reason that the present analysis focuses on the effect of immigration on United States natives, and further stratifies by elements such as race and type of social cohesion measured.

By using Current Population Survey September Supplement Volunteering data from 2004-2008 (just before and during the onset of the current recession), and controlling for immigrant location selection and income inequality, the present work represents a novel addition to the literature. The data is large, representative, recent and disaggregated. The structure I use makes a causal interpretation of immigration (the 1990-2000 cohort) as affecting the volunteering participation of native-born United States citizens more plausible than in other related studies. I use countylinked Core Based Statistical Area (CBSA) level area characteristics, as well as a measure of volunteering fifteen years prior, the average volunteering in the 1989 Current Population Survey, to account for immigrant location selection.

In robustness checks, I also employ a linear probability model to account for noise in my choice of instrumental variable with these additional results generally confirming those in the main analysis. Distinctions in results between the full sample of cities versus large, densely populated cities, I argue, explain differences in results more generally between the United States and Europe in analyses of volunteering, with the caveat that these differences may also show evidence for a limited effect of immigration on volunteering.

I find that large, densely populated cities in the United States look quite similar to cities in Europe in having little relationship between volunteering and immigration after accounting for income inequality. It turns out that the anomalous nature of the immigration-to-social-cohesion relationship in the United States as a whole is driven by the smaller and more sparsely populated cities in the United States. After all, Manhattan, Kansas is in a much less favorable position to deal with new immigrants than is Manhattan Beach, California or Manhattan, New York. Therefore, it is true that the full sample, which uses both large and small cities, does verify that native United States citizens are more likely to "bowl alone" when there are higher rates of immigration, and the question is whether this is a causal effect. The strength of the conclusions to be drawn is circumscribed, however, if it is the case that selection by natives is conditional on personality characteristics such as egocentricity. Accordingly, the ability of the present analysis to distinguish between these two hypotheses is limited.

In the final of the auxiliary analyses, I explore the effect of using voting, rather than volunteering, as the measure of social cohesion. While voting is a less commonly employed measure of social cohesion in this literature, and it is probably useful to consider voting at still smaller levels of aggregation - such as local area levels - these initial results are used as robustness checks for the negative relationship I generally find between social 
cohesion and immigration. I am currently extending these preliminary results on voting using more specific data at the local and tract level, which may be a better level of aggregation in the case of voting, in order to examine in more detail the mediating effect of city size.

Finally, in placing this work within the context of the existing literature, perhaps the most similar analyses to the present one are Costa and Kahn (2003) study using 1974 and 1989 data. They use less relevant, older data and, furthermore, do not account for selection or immigrant flows as I attempt to do here. Also, Alesina et al. (1999) found a negative effect of diversity but examined a slightly different outcome: whether individuals in communities with varying amounts of heterogeneity were more or less likely to vote to increase local taxes. They also used the smaller GSS rather than CPS data and did not find varying effects based on city size-in contrast to my results where city size does appear to matter. Finally, Alesina and La Ferrara (2002) looked at the outcome of "trust" rather than activities and volunteering, and used a fractionalization rather than a concentration approach as I do here - with some evidence that concentration measures provide a more straightforward analysis. In this last case, results in Alesina and La Ferrara's work show similar patterns to those in my analysis, although they use the smaller, and hence noisier, GSS data. Taken together, the present analysis presents a helpful and necessary addition to the growing literature in the area.

\section{Background and motivation}

\section{A. Economic and community decline}

From a business perspective, with lower levels of social cohesion there is less trust and lending, as well as higher default rates among microfinance cooperatives (Costa and Kahn 2003; Alesina and La Ferrara 2005; Putnam 2007), since individuals do not feel bound to maintain face before their friends and neighbors by not defaulting. There are also problems in innovation and coordination leading to successful competition in the international market by small vs. large firms. This has been pronounced in the case of Italy and several other European countries (Ramazzotti 2010). At a continental level, the seminal work by Easterly and Levine (1997) has shown that heterogeneity leading to decreased social cohesion in Africa is associated with more clans, more crime, more black markets, and much lower levels of country-wide growth than otherwise similar countries in the continent with lower levels of heterogeneity and higher social cohesion. These effects are understandably affected by levels of political stability and democratic rights.

Other work, however, has found little effect of crime in mitigating the social cohesion-diversity relationship. This is true although Putnam (2007) initially posited a very strong effect in this area (Alesina and La Ferrara 2002; Mohan et al. 2011).

At the community level, there is less fundraising in schools, lower rates of participation in social reform projects, fewer people volunteering or giving to charity, less contribution to schools, fewer friends, lower levels of happiness and more television watching (Putnam 2007; Poterba 1997). In a sense, one possibility is that with lower levels of social cohesion and more heterogeneous communities, there is simply more difficulty in sharing resources in ways individuals deem to be equitable (Alesina and La Ferrara 2002). While a lack of social cohesion owing to 
diversity may have the benefit of causing greater private production - or even "patronage", as in publicly provided private goods - (Alesina and La Ferrara 2005), there will be lower levels of provision of the public good and other ills just described, making it unclear which is really the best strategy to employ.

\section{B. Measuring social cohesion}

Social cohesion is generally conceived of as either social capital maintenance or else methods of creating solidarity and equality of access. While there are other conceptions and definitions of this term, these two appear to be the most commonly used in the literature and closest to their initial intent-especially in the burgeoning economics literature. Measures of social cohesion have included, as a few examples: membership in networks, social solidarities, membership in clubs/ associations/volunteer work, social trust, social order, common values, civic participation, and place attachment (Galabuzi and Teelucksingh 2010; Demireva 2011; Vigdor 2004). It is for this reason that the present analysis focuses on volunteering in clubs (the most frequently employed measure, aside from "general social trust") as well as employing measures of voting in one of the auxiliary analyses.

While social cohesion has been extensively discussed, there is no commonly agreed upon method for choosing the outcome (or outcomes, if multi-faceted and, perhaps, a "better" measure) representing social cohesion. It does appear that stated levels of trust or club participation (such as volunteering) have received the most support as measures of social capital maintenance. An additional reason for using club associations are their high documented correlation with social trust (Glaeser et al. 2000; Alesina and La Ferrara 2002) -although the direction of causality is unclear. Hence, the focus of the current work on volunteering behaviors.

The use of clubs and associations/volunteer memberships runs afoul of the possibility that these groups maintain the embedded class structure and reflect individuals that have access to resources. Scholars have begun to reconsider and give less credence to this idea, since membership in voluntary associations and religious groups has indeed become much more heterogeneous-exhibiting both "bridging" (relations to out-groups) as well as "bonding" (relations to the in-group) types of social capital. For the reasons mentioned above, voting is used to generally confirm and extend the main results of the present analysis.

\section{Immigration and social cohesion}

After seeing the societal ills an erosion of social cohesion can cause-either in the real world, theoretically, or in experimental games (Alesina and La Ferrara 2005) and after understanding what social cohesion actually means, it is apparent that when Putnam (2007) demonstrated that immigration (as a form of increasing ethnic and linguistic heterogeneity) in Italy eroded social cohesion, he caused quite a commotion. If, in fact, immigration causes a significant decline in social cohesion leading to economic decline, countries need to reevaluate their immigration policies. Although immigration and diversity in general has many, possibly longer-term, benefits, not the least of which are an increased opportunity for innovation by immigrant entrepreneurs and scientists, a richer culture, long-run growth, positive (or at least neutral) effects on native student achievement, and the benefits of "portfolio diversity insuring against risk" (Costa and Kahn 2003; Putnam 2007; 
Neymotin 2009), the negative effects are numerous. In terms of economic stability, it would then be very possible that it is these same effects which are responsible for our current economic decline.

For this reason, among others, a literature has recently developed to test the veracity of Putnam's claims and, more generally, the strength of the relationship between immigration/diversity and social cohesion worldwide. For the most part, evidence in the aforementioned and other studies showing that immigration and heterogeneity decrease social cohesion at the country level has been shown to be overstated, since accounting for income inequality decreases the strength of the stated relationship (Green et al. 2011; Kesler and Bloemraad 2010; Demireva 2011; Letki 2008;

Alesina and La Ferrara 2005). After including measures of inequality-whether Gini coefficients, the fraction of individuals below the poverty line, the 90/10 ratio, or the average to median income in communities or countries-the effect of immigration on social cohesion declines in magnitude and significance. This is especially true for European studies, with U.S. studies breaking with the general trend by generally maintaining a clear and significant effect of immigration in decreasing social cohesion (Becares 2011; Galabuzi and Teelucksingh 2010; Hooghe et al. 2009).

Nevertheless, some of the problems with which very few of these studies have been able to contend (whether Putnam's original study) or later work, have been

(1) difficulty controlling for selection based on preferences for local good provision,

(2) issues with the small size or highly-aggregated nature of the data, and

(3) difficulty finding credible measures of inequality and fractionalization. As Simpson (2006) notes, fractionalization may actually not be measuring what we want it to, so that the current reliance on the fractionalization index which is actually quite crude as a measure may be faulty. The present analysis is an attempt to address these issues.

Immigrants, generally a lower income group, will, on average, increase the number of people with "low levels of access," thus, the relationship is almost definitional. However, the use of income inequality may be more than a truism, since Putnam's definition of social cohesion falls closer to the idea of "social capital" and its maintenance. Unfortunately, many of the measures of both social capital and social cohesion as inequality reduction are very similar-making it difficult for researchers to decide exactly which ones to employ.

Work by Alesina and La Ferrara provides a good framework and reasons why immigrants should have lower levels of social trust and cohesion. Specifically, it could be said that immigrants exhibit many, if not all, of the characteristics of individuals likely to have reduced levels of social capital, and hence low social cohesion as measured by social capital maintenance. Immigrants are often in the lower income tiers, and may additionally suffer from discrimination-by language if not always by ethnicity, although generally the wave of Hispanic and Asian immigrants represents a minority to the United States. Also, immigrants have lived in the area for a shorter period of time with fewer ties to the location-although some would argue that, although individual immigrants have weaker ties to other individuals, their communal ties tend to be stronger than those for natives-see for example Gorney and Torunczyk-Ruiz (2011). Lastly, immigrants tend to locate in areas of higher income inequality (selection) making them less likely to have high social capital. 


\section{Materials and methods}

The main data employed for this analysis were the 2004-2008 Current Population Survey (CPS) September Volunteering Supplements. The 1989 CPS September Volunteering Supplement was also used to establish baseline average volunteering rates by CBSA and, therefore, represents a correction for immigrant location selection.

Earlier historic measures of volunteering in the community were used as an immigrant location selection correction due to concerns that current waves of immigrants select their location of choice conditional on economic conditions in the area. Because it is also true that immigrants tend to settle in historically high immigration areas, and historical measures of immigration should not generally correlate with current economic shocks, this measure is used to correct for the type of selection which may hinder the ability to determine the effect of immigration independent of local area characteristics. This selection correction is standard in the immigration literature (Dustmann et al. 2005; Card 2001; Bartel 1989). The historic measure has often been 20-30 years prior which is essentially the time difference for, at least the later, portion of data used here.

The CBSA level was chosen because it was the level typically employed by the Census during this wave, and was meant to replace and merge both Micropolitan and Metropolitan Statistical Areas. This more comprehensive measure is useful in later generalizing results, particularly for city size stratifications.

The September Supplements include a series of questions regarding (formal) volunteering activities and choices. As a caveat, employing formal, rather than informal volunteering, will, if anything, understate the relationship between volunteering and immigration due to the lower correlation between formal volunteering and social cohesion (Tong 2010; Letki 2008), so that measured relationships between volunteering and immigration may actually be even stronger than found in the current analysis.

The CPS, as opposed to the General Social Survey (GSS), which is typically used in these types of analyses, or other time diary data such as the American Time Use Survey (ATUS), was chosen due to its very large and representative nature and the particular breakdowns given to both immigrant status and type of volunteering. Auxiliary analyses on voting employed a similar structure and used the 2004, 2006 and 2008 CPS November Supplements. In the case of voting, the 1990 CPS November Supplement was used to establish baseline average volunteering rates by CBSA as the immigrant location selection correction.

Voting data employed from the CPS included a binary indicator for whether an individual had voted in the previous election. Volunteering information employed from the CPS data included a binary indicator for whether an individual volunteered their time, as well as indicators for whether the individual volunteered for several representative choices of organizations including (1) immigrant focused, (2) religious, (3) childfocused, (4) civic, (5) social service, and (6) international ${ }^{1}$.

Notice that volunteering for a child's education has many fewer immigrant volunteers since immigrant parents tend to have less information and perhaps self-concept regarding the ability to contribute. This concept of information as hindering the volunteering of immigrants is explored further in several sources (for example, see Gele and Harslof 2012; Handy and Greenspan 2009). Religious volunteering is also differentiated from the group, since immigrants tend to first be tied to religious organizations. It is posited 
that this is because religious groups may increase bonding, but not bridging capital in communities (Galabuzi and Teelucksingh 2010). Empirical results have not, however, found a strong effect of religion.

Individuals in the CPS who were foreign born (either non-citizens or naturalized citizens) were considered members of the first generation, while individuals born in the United States to either two foreign born parents or to one foreign and one native-U.S. parent were considered members of the second or 2.5 generation, respectively. Other individuals born in the United States-or abroad to U.S. parents as in Card et al. (2000) were considered members of the third (or higher) generation. For all immigrant stratifications, it was not possible to condition on legal status, since this information was not available in the 2000 Census or CPS data, although the Census did make efforts during this period to interview individuals of illegal immigrant status.

Individual ethnicity and country of origin was also used to account for immigration of one's racial/ethnic or country of origin type. In particular, Mexico, one of the largest countries of origin during this time period, is controlled for in a separate fashion. In contrast, due to data concerns, many other country-of-origin groups are limited to the continental or sub-continental level.

Additional individual-level characteristics employed from the Current Population Survey as control variables included age, sex, education, family income, race, the presence and ages of children, the number of individuals in the household and employment status. Notice that employment status was chosen rather than hours of work due to the more endogenous relationship between hours and volunteering. The analysis was restricted to individuals answering that they were of a single, rather than multiple, racial backgrounds.

In addition to Current Population Survey data, Census 2000 Summary files (3 and 4) were used to determine aggregate information in the area regarding immigration and local area characteristics. Data were matched from the Census Summary Files to the CPS using a CBSA-MSA match through counties. New England County Tabulation Areas (NECTA's) were dropped due to the coding structure.

The foreign-born individuals of interest from the Census data were the 1990-2000 cohort of immigrants. Country of birth of the immigrants, as well as race/ethnicity, employed the same categories as the CPS. Census information was also employed to create several alternate measures of inequality in the area, including the ratio of average to median family income, the fraction of the total population below the poverty line and the fraction of immigrants below the poverty line. Additional local area characteristics employed in the analysis included total population size and density, average age, employment rate, fraction of various racial groups, average education and median family income.

\section{Calculation}

The goal of the empirical analysis is to determine whether an inflow of immigrants affects the likelihood that natives will contribute to public goods and volunteer their time. In order to control for possible location selection of immigrants, average 1989 volunteering at the CBSA level is employed, and immigration is measured as the fraction of foreign born from the 1990-2000 cohort relative to the total population in the 
area. This empirical choice mitigates the problem of the immigration variable incorrectly picking up the tendency of immigrants to locate in areas with historically low levels of immigration-through the 1989 average volunteering control-and, therefore, create bias in the effect of immigration on the individual likelihood of volunteering. It is also true that native selection will be mitigated, since measures are taken at the CBSA-linked to county level, which should be a high-enough level of aggregation that there will be minimal sorting of natives at this level. Technically, the literature agrees on the county level for native sorting, and some work uses the MSA level. See for example Vigdor (2004).

Clearly, immigrants may prefer sorting by area even at this higher level of aggregation. For this reason, employing the previously mentioned average volunteering in 1989 will also be necessary to account for selection ${ }^{2}$.

This strategy will, therefore, show the effect of the 1990-2000 immigration on individual volunteering rates of natives in 2004-2008 after accounting for immigrant location selection bias conditional on average volunteering rates in the area. Prior research, particularly using European data, has also shown that measured impacts of immigration diminish after controlling for income inequality in the local area. For this reason, several measures of income inequality are alternatively employed to account for this possibility. Controls at the individual and the local area level are also progressively added in to the regression structure.

The main portion of the analysis employs a probit structure with marginal effects and clustering at the CBSA level to use the most conservative standard errors possible. Probability weights for sample inclusion are also employed. Specifically, for individual $i$ in local area $j$ :

$$
\begin{aligned}
\operatorname{Pr}\left(\text { Volunteer }_{i, j}\right. & =1 \mid \text { Demog }_{i}, \text { CommChar }_{j},{\text { Frac Im } \left.\text { mig }_{j}, \text { Inequality }_{j}\right)} \\
& =\Phi\left(\beta_{0} \text { Demog }_{i}+\beta_{1} \text { CommChar }_{j}+\beta_{2} \text { Frac Im mig }_{j}+\beta_{3} \text { Inequality }_{j}\right)
\end{aligned}
$$

Where $\Phi($.$) represents the cumulative normal distribution function.$

Volunteer is either an indicator for whether an individual volunteers generally or, in the appendix section, for a specified volunteer organization. In many cases, individuals volunteered for multiple different types of organizations. Demog represents demographic characteristics of the individual (age, age ${ }^{2}$, sex, education, family income, race, the presence of children, number of individuals in the household, and employment status). Since "natives" include any individuals from the 2nd, 2.5 or 3rd (or later) generation, Demog also includes binary indicators for the generational status of the native in question-as well as whether the foreign parent is the mother or father in the case of the 2.5 generation. Additional robustness checks vary this structure and separately examine the effect of immigration on the volunteering choices of the subset of 3rd (or later) generation or, alternatively, 2nd generation natives. CommChar include community area average characteristics (total population, population density, average age, employment rate, fraction representation of various racial groups, education and median family income $)^{3}$.

Inequality represents either (a) the fraction of individuals in the total population below the poverty line, (b) the fraction of immigrants below the poverty line or (c) the ratio of average to median family income in the area. Notice that measures of income 
inequality were employed since (1) income inequality may matter more at low levels of income (fraction below poverty), (2) it may be that immigrants have an indirect effect via their levels of poverty (fraction immigrants below poverty) see Gustavsson and Jordahl (2006), or else (3) distribution and skewness made the key difference as in Alesina et al. (1999). All three measures were employed in order to contrast these differing theories for why income inequality may affect social cohesion and generally determine whether statements could be made regarding the more "general" relationship with income inequality.

Finally, FracImmig represents the fraction of 1990-2000 cohort immigrants relative to the total population in the local CBSA area. Alternatively, it represents the fraction of this cohort of immigrants stratified by (a) race/ethnicity, and (b) country of origin. Own-ethnic/country/cohort effects are explored as well-with a focus on groups with larger numbers of immigrants during this period. It is worth reiterating that the community characteristics control for the percentage of various ethnic representations, so that immigration is not instead picking up ethnic effects as well as this measure of diversity (See Holtug (2010) for a similar empirical distinction). It is also beneficial to use wave of immigration (1990-2000 foreign born) in the current analysis to mitigate this issue. In addition, concentration measures are used for both the inequality and immigration measures due to recent evidence regarding their possible superiority and ease of interpretation (Simpson 2006).

Following the work of Friedberg and Jaeger (2009), it was posited that there might be a different relationship between immigration and volunteering in larger cities. In contrast to the main hypothesis of this analysis, it could be that natives selectively locate in larger or smaller cities conditional on their personal proclivity for individualism. If this is the case, then main analysis results may mask this selection by averaging over different types of cities. For this reason, the analysis was restricted to CBSA's/MSA's with a total population in the Census 2000 over 1,000,000 and a population density greater than 0.001 -robustness checks varied these boundaries with little or no change in effect. Since the amount and type of immigration can affect other average characteristics of the local area, this reasoning was part of the impetus for also exploring regressions without a subset of the specific city-characteristics, in addition to the baseline structure mentioned above, for example, dropping the controls for total population, population density, average age, employment rate, and education at the area level. In this way, it was possible to determine how immigrants affect both local characteristics and directly impact volunteering.

As a robustness check, the probit regression structure was varied to employ a linearized regression structure. The reason for this empirical decision was that the 1989 CPS supplements were constructed using a relatively small sample, so that noise from employing a probit structure could obscure the true size of the coefficients. A linearized regression, while not necessarily the optimal choice generally, would, in this scenario, allow for less noisy results. The linear model was run using various instantiations with, alternatively the coefficient on the average volunteering in the community (the selection correction) being (a) unconstrained, (b) $=1,(\mathrm{c})=0.5$. It is notable that (b) is similar to a differencing analysis ${ }^{4}$.

In a final auxiliary analysis, the regressions from the main analysis were run using the outcome of whether individuals voted, rather than whether they 
volunteered. In this case, the immigrant location selection correction was the 1990 average voting in the community. Since the 1990 sample used for the voting selection correction did not suffer from the same sort of sample size issues as the 1989 supplements, the linearized regression was not employed for the voting regressions. There was only one "type" of voting, however, it was disaggregated by city size as well as employing or not employing various area level characteristics in the regressions.

\section{Results and discussion}

\section{A. Descriptive statistics}

Figures 1 and 2 display the immigration and volunteering rates in the United States. Data for immigration come from the Census 2000 Summary Files, while data for volunteering come from the Current Population Survey 2004-2008 September Supplement files. Data in both figures are restricted to states used in the main regression portion of the analysis. The figures generally show an inverse relationship between the fraction foreign born in a state and volunteering rates in the state with higher immigration in low volunteering states, and vice versa.

Perhaps the starkest example is New York, lying in the highest category of immigration (19-27\%) and the lowest category of volunteering (20-23\%). States with high immigration rates such as California, Illinois, and Texas have generally mid-level or lower volunteering rates. Rarely is a state in the same category for volunteering and immigration (Louisiana, Tennessee and Arkansas are notable exceptions). Overall, this initial introduction to the topic provides some preliminary evidence for the idea that in the United States, high immigration is related to lower levels of social cohesion and voluntary participation.

In Table 1, means are shown along with minimum and maximum values for each of the variables used in the main (i.e. non-voting) regression analysis. Results from the November Supplements are similar. The mean is further stratified by whether

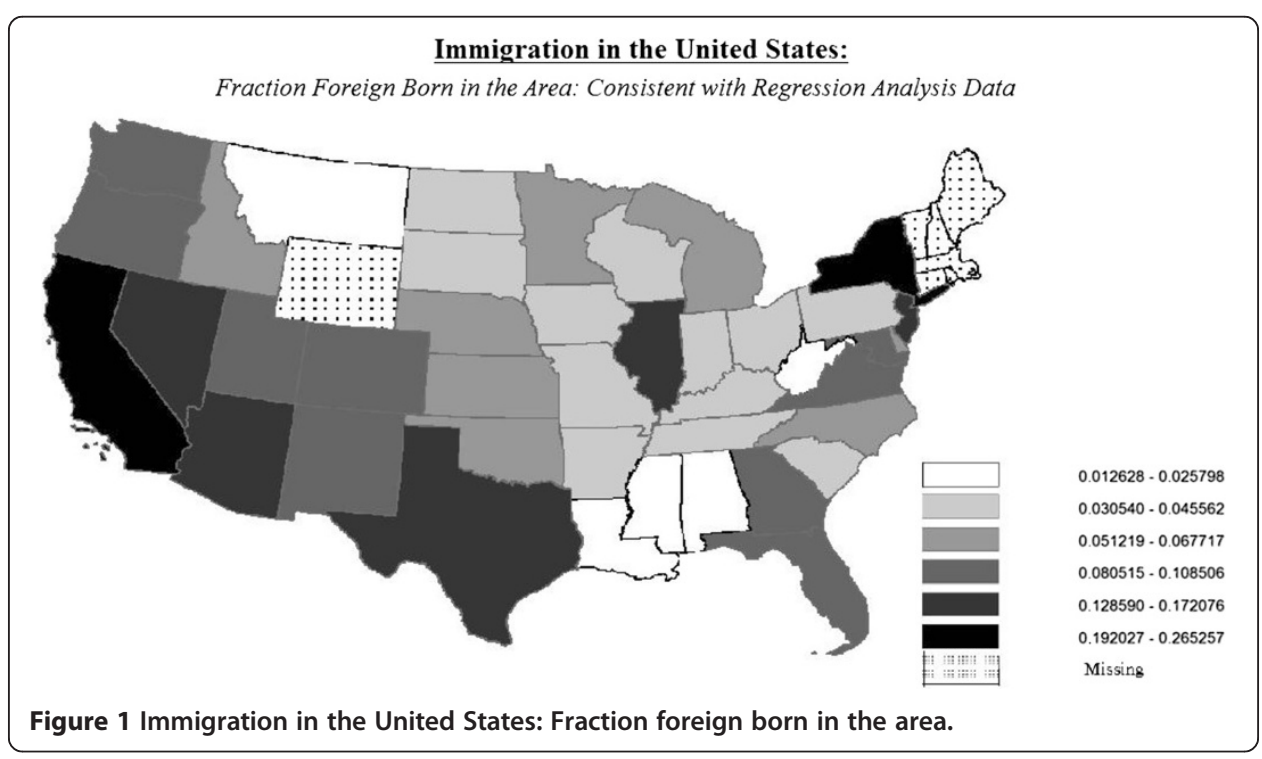




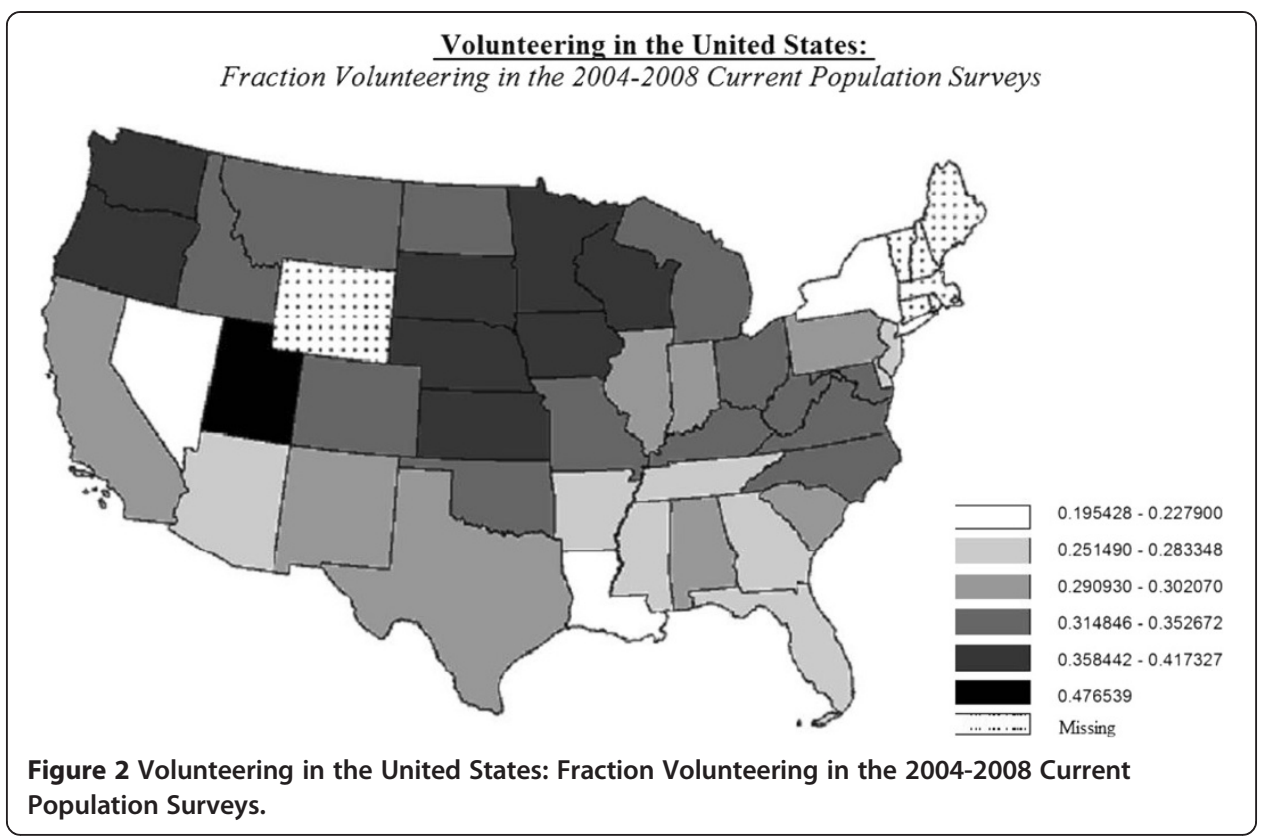

individuals answered all questions required for the regression analysis-which means this was a larger restriction than in any of the individual regressions. Individuals answering all relevant questions are labeled as part of the "controlled" sample for this table. Variables are grouped into whether they refer to immigration (coming from both the Census and the CPS data), individual characteristics (CPS), inequality measures (Census), or volunteering variables (CPS). As seen from a comparison of the controlled and the uncontrolled samples, individuals answering all questions were slightly different from individuals in the full sample-but not in unexpected ways. Specifically, the controlled sample had older individuals (age 44 subsample vs. age 37 full sample), fewer males ( $47.5 \%$ vs. $48.4 \%$ in the full sample) and fewer racial minorities-both individually and in terms of location choice.

These differences are unsurprising given typical survey response patterns with, for example, women and retirees more likely to answer surveys.

Income and education have similar means in both groups. Immigrant status shows more first-generation individuals and fewer second and 2.5 generation individuals in the sub-sample. This may be due to immigrants feeling an urge to "do their civic duty" in answering CPS survey questions. In keeping with concerns on this issue, it also implies that illegal immigrants might not constitute a large fraction of this data. There was also a somewhat higher representation of individuals with children of all ages in the data-consistent with expectations-as well as a slightly higher representation of individuals doing volunteer work, both overall and in particular categories.

In total, there were no surprising patterns in the survey responses, with the one interesting result being higher rates of completion by first generation individuals. Average volunteering also seems to have increased between 1989 and the 2004-2008 period. Although this may seem anomalous, given the predicted decreases over time, this result is likely due to changes in survey coding and slight variations in the 
Table 1 Summary statistics ${ }^{a}$

\begin{tabular}{|c|c|c|c|c|}
\hline & Uncontrolled & Controlled & Min & Max \\
\hline First generation & $13.0 \%$ & $15.3 \%$ & 0 & 1 \\
\hline Second generation & $6.6 \%$ & $4.1 \%$ & 0 & 1 \\
\hline 2.5 generation & $4.6 \%$ & $4.3 \%$ & 0 & 1 \\
\hline 2.5 Generation-mom foreign & $2.2 \%$ & $2.0 \%$ & 0 & 1 \\
\hline 2.5 Generation-dad foreign & $2.5 \%$ & $2.3 \%$ & 0 & 1 \\
\hline Fraction immigrants ( $90-00$ cohort) census & $5.0 \%$ & $4.9 \%$ & 0 & 0.12 \\
\hline Age & 36.991 & 44.041 & 1 & 85 \\
\hline Male & $48.4 \%$ & $47.5 \%$ & 0 & 1 \\
\hline White & $66.0 \%$ & $69.3 \%$ & 0 & 1 \\
\hline Black & $12.5 \%$ & $11.5 \%$ & 0 & 1 \\
\hline Asian & $5.4 \%$ & $5.3 \%$ & 0 & 1 \\
\hline American Indian & $0.4 \%$ & $0.4 \%$ & 0 & 1 \\
\hline Hispanic & $15.7 \%$ & $13.4 \%$ & 0 & 1 \\
\hline$<\$ 5000$ & $2.5 \%$ & $2.3 \%$ & 0 & 1 \\
\hline$\$ 5000-\$ 7499$ & $1.8 \%$ & $1.7 \%$ & 0 & 1 \\
\hline$\$ 7500-\$ 9999$ & $1.8 \%$ & $1.8 \%$ & 0 & 1 \\
\hline$\$ 10000-\$ 12499$ & $2.6 \%$ & $2.6 \%$ & 0 & 1 \\
\hline$\$ 12500-\$ 14999$ & $2.6 \%$ & $2.5 \%$ & 0 & 1 \\
\hline$\$ 15000-\$ 19999$ & $4.1 \%$ & $4.2 \%$ & 0 & 1 \\
\hline$\$ 20000-\$ 24999$ & $5.3 \%$ & $5.4 \%$ & 0 & 1 \\
\hline$\$ 25000-\$ 29999$ & $5.6 \%$ & $5.7 \%$ & 0 & 1 \\
\hline$\$ 30000-\$ 34999$ & $6.1 \%$ & $6.1 \%$ & 0 & 1 \\
\hline$\$ 35000-\$ 39999$ & $5.5 \%$ & $5.4 \%$ & 0 & 1 \\
\hline$\$ 40000-\$ 49999$ & $8.9 \%$ & $9.1 \%$ & 0 & 1 \\
\hline$\$ 50000-\$ 59999$ & $9.0 \%$ & $9.1 \%$ & 0 & 1 \\
\hline$\$ 60000-\$ 74999$ & $11.3 \%$ & $11.2 \%$ & 0 & 1 \\
\hline$>\$ 75000$ & $32.9 \%$ & $33.0 \%$ & 0 & 1 \\
\hline$<1$ st grade & $0.4 \%$ & $0.3 \%$ & 0 & 1 \\
\hline 1-4th grade & $0.8 \%$ & $0.8 \%$ & 0 & 1 \\
\hline 5-6th grade & $1.7 \%$ & $1.6 \%$ & 0 & 1 \\
\hline 7-8th grade & $2.3 \%$ & $2.2 \%$ & 0 & 1 \\
\hline 9th grade & $3.3 \%$ & $3.2 \%$ & 0 & 1 \\
\hline 10th grade & $3.9 \%$ & $3.8 \%$ & 0 & 1 \\
\hline 11th grade & $4.0 \%$ & $3.9 \%$ & 0 & 1 \\
\hline 12th grade no diploma & $1.5 \%$ & $1.4 \%$ & 0 & 1 \\
\hline H.S. Grad. & $28.6 \%$ & $27.4 \%$ & 0 & 1 \\
\hline Some college & $18.2 \%$ & $18.4 \%$ & 0 & 1 \\
\hline Associate degree vocational & $3.9 \%$ & $3.9 \%$ & 0 & 1 \\
\hline Associate degree academic & $3.8 \%$ & $3.9 \%$ & 0 & 1 \\
\hline B.S. degree & $18.2 \%$ & $19.0 \%$ & 0 & 1 \\
\hline M.A. degree & $6.6 \%$ & $7.1 \%$ & 0 & 1 \\
\hline Professional degree & $1.5 \%$ & $1.6 \%$ & 0 & 1 \\
\hline Doctorate & $1.2 \%$ & $1.3 \%$ & 0 & 1 \\
\hline Presence of kids age 0-2 & $5.9 \%$ & $8.0 \%$ & 0 & 1 \\
\hline
\end{tabular}


Table 1 Summary statistics ${ }^{\mathbf{a}}$ (Continued)

\begin{tabular}{|c|c|c|c|c|}
\hline Presence of kids age 3-5 & $6.1 \%$ & $8.2 \%$ & 0 & 1 \\
\hline Presence of kids age 6-13 & $12.1 \%$ & $15.9 \%$ & 0 & 1 \\
\hline Presence of kids age 14-17 & $7.6 \%$ & $9.6 \%$ & 0 & 1 \\
\hline Number in the household & 3.336 & 2.998 & 1 & 16 \\
\hline Employed & $62.5 \%$ & $64.0 \%$ & 0 & 1 \\
\hline Unemployed & $3.2 \%$ & $3.4 \%$ & 0 & 1 \\
\hline Not in the labor force & $34.3 \%$ & $32.7 \%$ & 0 & 1 \\
\hline Median Family Income (MSA) & $5 . E+04$ & $5 . E+04$ & 26009 & 80036 \\
\hline Total Population (MSA) & $4 . E+06$ & 4.E+06 & 82946 & 16373645 \\
\hline Average Age (MSA) & 35.14 & 35.13 & 27.30 & 49.46 \\
\hline Employment Rate (MSA) & $71.1 \%$ & $71.4 \%$ & 0.53 & 0.84 \\
\hline Graduate Degree (MSA) & $8.6 \%$ & $8.7 \%$ & 0.03 & 0.18 \\
\hline B.S. Degree (MSA) & $16.1 \%$ & $16.3 \%$ & 0.06 & 0.26 \\
\hline Associate Degree (MSA) & $6.1 \%$ & $6.1 \%$ & 0.02 & 0.12 \\
\hline Some College (MSA) & $23.7 \%$ & $23.7 \%$ & 0.15 & 0.38 \\
\hline High School Grad. (MSA) & $26.7 \%$ & $26.7 \%$ & 0.18 & 0.49 \\
\hline Some High School (MSA) & $12.4 \%$ & $12.3 \%$ & 0.04 & 0.20 \\
\hline Fraction below poverty & $11.6 \%$ & $11.4 \%$ & 0.05 & 0.36 \\
\hline Fraction immigrants below poverty & $5.3 \%$ & $5.2 \%$ & 0.00 & 0.25 \\
\hline Average to median income ratio & 1.278 & 1.278 & 1.14 & 1.69 \\
\hline Average volunteering (1989)-group level & $21.5 \%$ & $21.8 \%$ & 0 & 0.57 \\
\hline Average volunteering (2004-8)-indivl. level & $28.4 \%$ & $29.4 \%$ & 0 & 1 \\
\hline Immigration & $0.1 \%$ & $0.1 \%$ & 0 & 1 \\
\hline Religious & $11.8 \%$ & $12.5 \%$ & 0 & 1 \\
\hline For kids & $7.3 \%$ & $7.8 \%$ & 0 & 1 \\
\hline Social services & $5.4 \%$ & $5.7 \%$ & 0 & 1 \\
\hline Civic & $1.5 \%$ & $1.6 \%$ & 0 & 1 \\
\hline International & $0.2 \%$ & $0.2 \%$ & 0 & 1 \\
\hline
\end{tabular}

${ }^{a}$ Means are displayed for the sample of all individuals (uncontrolled) as well as the sample who answered all questions for variables used at any time in the volunteering regression analysis, (controlled). The minimum and maximum is displayed for the uncontrolled sample.

context of questions. It should not be interpreted too strongly, especially since 1989 average volunteering is only used as a control for average levels in previous years and not in a panel structure in the present analysis.

B. Main regression analysis

All regressions were run at the individual level using probability weighting for sample inclusion, binary indicators for year and region, and clustering of standard errors on CBSA to allow for the most conservative estimates possible. Unless stated otherwise, it can be assumed that the regressions were run with full controls for individual and local area characteristics as described in the data and empirical section. Coefficients from marginal probit regressions are displayed, along with the absolute value of their associated t-statistics. Many of the regressions also display two different panels of results using individuals in all cities, as well as using the subsample of individuals in large and densely populated cities. The fraction of foreign born variables refer, in all cases, to those foreign born individuals coming from the 1990- 
2000 cohort of immigrants relative to the total population in the CBSA, or else the number of 1990-2000 cohort immigrants by race/country of origin relative to the total population in the city when more appropriate.

In Table 2, there are four regressions for each of the full sample of cities (Panel A), as well as the large-city-only sample (Panel B) providing a total of eight regressions in this table. The first two regressions in each panel have neither individual nor area-level characteristics-other than year, region (and average income in Table 2)while the third and fourth regressions progressively add in the full set of individual and area-level control characteristics. The exception being the immigrant location selection correction (average volunteering in 1989) and measures of income inequality, which are instead included in regressions used for Tables 3, 4, 5 and the appendices.

Although it is standard to progressively add in controls, this structure is explicitly emphasized here because of the possibility that the relationship between diversity and social cohesion is changed when accounting for individual characteristics, or because immigration actually causes some of the local average characteristics (see Alesina and La Ferrara 2002, 2005). Later tables also rerun regressions with a smaller number of local area controls with similar findings.

Table 2 Effect of foreign born on volunteering ${ }^{a}$

\begin{tabular}{|c|c|c|c|c|}
\hline Individual controls & - & - & $x$ & $x$ \\
\hline Area level controls & - & - & - & $\mathbf{x}$ \\
\hline Panel A: All cities & [1] & [2] & {$[3]$} & [4] \\
\hline \multirow[t]{2}{*}{ Fraction foreign born } & -0.384 & -0.292 & -0.667 & -1.315 \\
\hline & {$[1.70]$} & {$[1.31]$} & {$[3.80]^{* *}$} & {$[3.51]^{* *}$} \\
\hline \multirow[t]{2}{*}{2.5 Gen-dad foreign (Binary) } & & 0.001 & 0.028 & 0.03 \\
\hline & & {$[0.12]$} & {$[3.56]^{* *}$} & {$[3.54]^{* *}$} \\
\hline \multirow[t]{2}{*}{2.5 Gen-mom foreign (Binary) } & & 0.004 & 0.005 & 0.006 \\
\hline & & {$[0.46]$} & {$[0.53]$} & {$[0.64]$} \\
\hline \multirow[t]{3}{*}{ Second gen. (Binary) } & & -0.077 & -0.02 & -0.015 \\
\hline & & {$[12.74]^{* *}$} & {$[3.17]^{* *}$} & {$[2.11]^{*}$} \\
\hline & 239059 & 239059 & 202518 & 202518 \\
\hline Panel B: Big cities & [1] & [2] & {$[3]$} & [4] \\
\hline \multirow[t]{2}{*}{ Fraction foreign born } & -0.552 & -0.458 & -0.642 & -0.287 \\
\hline & {$[2.12]^{*}$} & {$[1.79]$} & {$[2.94]^{* *}$} & {$[0.55]$} \\
\hline \multirow[t]{2}{*}{2.5 Gen-dad foreign (Binary) } & & 0.007 & 0.031 & 0.033 \\
\hline & & {$[0.68]$} & {$[3.20]^{* *}$} & {$[3.62]^{* *}$} \\
\hline \multirow[t]{2}{*}{ 2.5 Gen-mom foreign (Binary) } & & 0.011 & 0.009 & 0.009 \\
\hline & & [1.05] & {$[0.77]$} & {$[0.87]$} \\
\hline \multirow[t]{2}{*}{ Second gen. (Binary) } & & -0.08 & -0.026 & -0.021 \\
\hline & & {$[15.33]^{* *}$} & {$[3.58]^{* *}$} & {$[3.07]^{* *}$} \\
\hline Observations & 133284 & 133284 & 111699 & 111699 \\
\hline
\end{tabular}

${ }^{a}$ Coefficients are shown along with absolute values of t-statistics for the eight regressions of interest. All regressions use probability weights for sample inclusion and clustering on the highest relevant level for the most conservative standard errors possible in the analysis. All regressions further include controls for year and region. Individual characteristics added into the analysis in column 3 include age, age ${ }^{2}$, sex, education, family income, race, the presence of children, number of individuals in the household and employment status. Area characteristics added into the analysis in column 4 include total population, population density, average age, employment rate, fraction of various race groups, education and median family income. ${ }^{*}$ and ${ }^{* *}$ show statistical significance at the $5 \%$ and the $1 \%$ level respectively. 
Table 3 Effect of fraction foreign born on volunteering ${ }^{a}$

\begin{tabular}{|c|c|c|c|c|c|c|c|c|c|}
\hline \multirow[t]{4}{*}{ Panel A: All cities } & \multicolumn{3}{|c|}{ Inequality measure: } & \multicolumn{3}{|c|}{ Inequality measure: } & \multicolumn{3}{|c|}{ Inequality measure: } \\
\hline & \multicolumn{3}{|c|}{ Fraction foreign born below poverty } & \multicolumn{3}{|c|}{ Mean to median income } & \multicolumn{3}{|c|}{ Fraction below poverty } \\
\hline & Full sample & $3+$ gen & 2nd gen & Full sample & $3+$ gen & 2nd gen & Full sample & $3+$ gen & 2nd gen \\
\hline & [1] & {$[2]$} & [3] & [4] & {$[5]$} & {$[6]$} & [7] & [8] & [9] \\
\hline \multirow[t]{2}{*}{ Fraction foreign born } & -1.213 & -1.189 & -1.189 & -1.234 & -1.193 & -1.969 & -1.34 & -1.294 & -1.668 \\
\hline & {$[3.27]^{* *}$} & {$[3.21]^{* *}$} & {$[3.50]^{* *}$} & {$[3.38]^{* *}$} & {$[3.29]^{* *}$} & {$[5.13]^{* *}$} & {$[3.62]^{* *}$} & {$[3.45]^{* *}$} & {$[3.77]^{* *}$} \\
\hline \multirow[t]{2}{*}{ Second gen. (Binary) } & -0.014 & & & -0.013 & & & -0.013 & & \\
\hline & [1.89] & & & {$[1.78]$} & & & {$[1.77]$} & & \\
\hline \multirow[t]{2}{*}{ 2.5 Gen-mom foreign (Binary) } & 0.007 & & & 0.008 & & & 0.008 & & \\
\hline & {$[0.80]$} & & & {$[0.87]$} & & & {$[0.85]$} & & \\
\hline \multirow[t]{2}{*}{2.5 Gen-dad foreign (Binary) } & 0.032 & & & 0.032 & & & 0.032 & & \\
\hline & {$[3.79]^{* *}$} & & & {$[3.81]^{* *}$} & & & {$[3.80]^{* *}$} & & \\
\hline \multirow[t]{2}{*}{ Average volunteering 1989} & 0.193 & 0.186 & 0.273 & 0.197 & 0.187 & 0.284 & 0.212 & 0.2 & 0.264 \\
\hline & {$[3.00]^{* *}$} & {$[2.79]^{* *}$} & {$[3.19]^{* *}$} & {$[3.14]^{* *}$} & {$[2.89]^{* *}$} & {$[3.62]^{* *}$} & {$[3.23]^{* *}$} & {$[2.94]^{* *}$} & {$[3.28]^{* *}$} \\
\hline \multirow[t]{2}{*}{ Inequality measure } & -0.032 & -0.021 & 0 & 0.004 & -0.021 & 0.815 & -0.53 & -0.449 & -0.423 \\
\hline & {$[0.60]$} & {$[0.39]$} & {$[0.00]$} & [0.03] & {$[0.13]$} & {$[3.10]^{* *}$} & {$[1.30]$} & {$[1.06]$} & {$[0.68]$} \\
\hline Observations & 181426 & 163394 & 8725 & 182653 & 164529 & 8764 & 182653 & 164529 & 8764 \\
\hline \multirow[t]{4}{*}{ Panel B: Large cities } & \multicolumn{3}{|c|}{ Inequality measure: } & \multicolumn{3}{|c|}{ Inequality measure: } & \multicolumn{3}{|c|}{ Inequality measure: } \\
\hline & \multicolumn{3}{|c|}{ Fraction foreign born below poverty } & \multicolumn{3}{|c|}{ Mean to median income } & \multicolumn{3}{|c|}{ Fraction below poverty } \\
\hline & Full sample & $3+$ gen & 2nd gen & Full sample & $3+$ gen & 2nd gen & Full sample & $3+$ gen & 2nd gen \\
\hline & [1] & [2] & [3] & [4] & {$[5]$} & [6] & [7] & [8] & [9] \\
\hline \multirow[t]{2}{*}{ Fraction foreign born } & -0.213 & -0.156 & -1.438 & -0.308 & -0.246 & -1.928 & -0.297 & -0.222 & -1.223 \\
\hline & {$[0.46]$} & {$[0.34]$} & {$[2.06]^{*}$} & {$[0.67]$} & {$[0.56]$} & {$[2.66]^{* *}$} & {$[0.56]$} & {$[0.45]$} & {$[1.13]$} \\
\hline \multirow[t]{2}{*}{ Second gen. (Binary) } & -0.02 & & & -0.02 & & & -0.02 & & \\
\hline & {$[2.63]^{* *}$} & & & {$[2.59]^{* *}$} & & & {$[2.63]^{* *}$} & & \\
\hline
\end{tabular}


Table 3 Effect of fraction foreign born on volunteering ${ }^{a}$ (Continued)

\begin{tabular}{|c|c|c|c|c|c|c|c|c|c|}
\hline \multirow[t]{2}{*}{2.5 Gen-mom foreign (Binary) } & 0.009 & & & 0.009 & & & 0.009 & & \\
\hline & {$[0.78]$} & & & {$[0.78]$} & & & {$[0.78]$} & & \\
\hline \multirow[t]{2}{*}{ 2.5 Gen-dad foreign (Binary) } & 0.032 & & & 0.032 & & & 0.032 & & \\
\hline & {$[3.25]^{* *}$} & & & {$[3.22]^{* *}$} & & & {$[3.23]^{* *}$} & & \\
\hline \multirow[t]{2}{*}{ Average volunteering 1989} & 0.098 & 0.083 & 0.342 & 0.112 & 0.095 & 0.381 & 0.111 & 0.093 & 0.316 \\
\hline & {$[0.92]$} & {$[0.73]$} & {$[2.19]^{*}$} & {$[1.07]$} & {$[0.87]$} & {$[2.79]^{* *}$} & {$[1.00]$} & {$[0.79]$} & {$[2.25]^{*}$} \\
\hline \multirow[t]{2}{*}{ Inequality measure } & -0.079 & -0.065 & 0.077 & -0.247 & -0.258 & 1.584 & 0.038 & 0.056 & 0.491 \\
\hline & {$[1.34]$} & {$[1.08]$} & {$[0.57]$} & {$[0.98]$} & {$[1.02]$} & {$[3.98]^{* *}$} & {$[0.04]$} & {$[0.06]$} & [0.19] \\
\hline Observations & 103937 & 91713 & 6353 & 103937 & 91713 & 6353 & 103937 & 91713 & 6353 \\
\hline
\end{tabular}

(Full Controls, Various Inequality Measures).

a Coefficients are shown along with absolute values of t-statistics for the eighteen regressions of interest. All regressions use probability weights for sample inclusion and clustering on the highest relevant level for the

most conservative standard errors possible in the analysis. All regressions further include controls for year an

by inequality measure employed city size status, as well as whenther natives in the sample of for

by inequality measure employed, city size status, as well as whether the natives in the sample of interest are the full group, the 3rd-plus or the second generation of natives. * and ** show statistical significance at the
$5 \%$ and the $1 \%$ level respectively. 
Table 4 Effect of fraction foreign born by race on volunteering ${ }^{a}$

\begin{tabular}{|c|c|c|c|c|c|c|c|c|c|}
\hline \multirow[t]{4}{*}{ Panel A: All cities } & \multirow{2}{*}{\multicolumn{3}{|c|}{$\begin{array}{c}\text { Inequality measure: } \\
\text { Frac foreign born below pov. }\end{array}$}} & \multirow{2}{*}{\multicolumn{3}{|c|}{$\begin{array}{c}\text { Inequality measure: } \\
\text { Mean to median income }\end{array}$}} & \multirow{2}{*}{\multicolumn{3}{|c|}{$\begin{array}{l}\text { Inequality measure: } \\
\text { Fraction below poverty }\end{array}$}} \\
\hline & & & & & & & & & \\
\hline & Full sample & $3+$ gen & 2nd gen & Full sample & $3+$ gen & 2nd gen & Full sample & $3+$ gen & 2nd gen \\
\hline & [1] & [2] & [3] & [4] & [5] & [6] & [7] & [8] & [9] \\
\hline \multirow[t]{2}{*}{ Fraction foreign born Asian } & 8.146 & 8.685 & 3.077 & 8.118 & 8.427 & 3.801 & 8.374 & 8.655 & 4.565 \\
\hline & {$[3.81]^{* *}$} & {$[3.90]^{* *}$} & {$[0.80]$} & {$[4.11]^{* *}$} & {$[4.05]^{* *}$} & {$[1.07]$} & {$[4.22]^{* *}$} & {$[4.12]^{* *}$} & [1.43] \\
\hline \multirow[t]{2}{*}{ Fraction foreign born hisp. } & -1.461 & -1.531 & -0.492 & -1.317 & -1.351 & -1.251 & -1.646 & -1.672 & -0.735 \\
\hline & {$[2.84]^{* *}$} & {$[2.98]^{* *}$} & [0.63] & {$[2.64]^{* *}$} & {$[2.72]^{* *}$} & {$[1.68]$} & {$[3.17]^{* *}$} & {$[3.20]^{* *}$} & {$[1.00]$} \\
\hline \multirow[t]{2}{*}{ Fraction foreign born white } & -4.581 & -4.349 & -7.598 & -4.778 & -4.57 & -6.788 & -4.651 & -4.435 & -7.388 \\
\hline & {$[4.09]^{* *}$} & {$[3.98]^{* *}$} & {$[5.66]^{* *}$} & {$[4.57]^{* *}$} & {$[4.48]^{* *}$} & {$[4.64]^{* *}$} & {$[4.39]^{* *}$} & {$[4.29]^{* *}$} & {$[5.57]^{* *}$} \\
\hline \multirow[t]{2}{*}{ Second gen. (0/1) } & -0.014 & & & -0.014 & & & -0.014 & & \\
\hline & {$[2.03]^{*}$} & & & {$[2.04]^{*}$} & & & {$[2.03]^{*}$} & & \\
\hline \multirow[t]{2}{*}{2.5 Gen-mom foreign $(0 / 1)$} & 0.008 & & & 0.009 & & & 0.009 & & \\
\hline & {$[0.93]$} & & & {$[1.05]$} & & & {$[1.03]$} & & \\
\hline \multirow[t]{2}{*}{2.5 Gen-dad foreign $(0 / 1)$} & 0.032 & & & 0.032 & & & 0.032 & & \\
\hline & {$[3.96]^{* *}$} & & & {$[4.15]^{* *}$} & & & {$[4.12]^{* *}$} & & \\
\hline \multirow[t]{2}{*}{ Average volunteering 1989} & 0.186 & 0.177 & 0.274 & 0.191 & 0.181 & 0.264 & 0.209 & 0.199 & 0.255 \\
\hline & {$[3.03]^{* *}$} & {$[2.79]^{* *}$} & {$[3.26]^{* *}$} & {$[3.22]^{* *}$} & {$[2.94]^{* *}$} & {$[3.40]^{* *}$} & {$[3.36]^{* *}$} & {$[3.06]^{* *}$} & {$[3.18]^{* *}$} \\
\hline \multirow[t]{2}{*}{ Inequality measure } & -0.049 & -0.043 & 0.013 & -0.139 & -0.149 & 0.447 & -0.58 & -0.562 & 0.11 \\
\hline & {$[0.95]$} & {$[0.80]$} & [0.11] & {$[0.93]$} & {$[0.96]$} & {$[1.46]$} & {$[1.43]$} & {$[1.31]$} & {$[0.19]$} \\
\hline Observations & 179129 & 161268 & 8654 & 180356 & 162403 & 8693 & 180356 & 162403 & 8693 \\
\hline
\end{tabular}


Table 4 Effect of fraction foreign born by race on volunteering ${ }^{a}$ (Continued)

\begin{tabular}{|c|c|c|c|c|c|c|c|c|c|}
\hline \multirow[t]{4}{*}{ Panel B: Large cities } & \multicolumn{3}{|c|}{ Inequality measure: } & \multicolumn{3}{|c|}{ Inequality measure: } & \multirow{2}{*}{\multicolumn{3}{|c|}{$\begin{array}{l}\text { Inequality measure: } \\
\text { Fraction below poverty }\end{array}$}} \\
\hline & \multicolumn{3}{|c|}{ Frac foreign born below pov. } & \multicolumn{3}{|c|}{ Mean to median income } & & & \\
\hline & Full sample & $3+$ gen & 2nd gen & Full sample & $3+$ gen & 2nd gen & Full sample & $3+$ gen & 2nd gen \\
\hline & [1] & [2] & [3] & [4] & {$[5]$} & [6] & [7] & [8] & [9] \\
\hline \multirow[t]{2}{*}{ Fraction foreign born Asian } & 12.746 & 13.788 & 5.924 & 12.394 & 13.441 & 3.954 & 12.335 & 13.415 & 6.628 \\
\hline & {$[4.53]^{* *}$} & {$[4.86]^{* *}$} & [1.04] & {$[4.55]^{* *}$} & {$[4.97]^{* *}$} & {$[0.59]$} & {$[3.92]^{* *}$} & {$[4.42]^{* *}$} & [1.12] \\
\hline \multirow[t]{2}{*}{ Fraction foreign born hisp. } & 0.25 & 0.11 & 0.274 & 0.07 & -0.078 & -0.519 & 0.249 & 0.114 & 0.839 \\
\hline & {$[0.62]$} & {$[0.25]$} & [0.32] & {$[0.16]$} & {$[0.17]$} & [0.49] & {$[0.53]$} & {$[0.23]$} & [0.88] \\
\hline \multirow[t]{2}{*}{ Fraction foreign born white } & -7.076 & -6.896 & -11.245 & -7.272 & -7.065 & -8.727 & -6.743 & -6.595 & -10.94 \\
\hline & {$[5.38]^{* *}$} & {$[4.97]^{* *}$} & {$[4.32]^{* *}$} & {$[5.32]^{* *}$} & {$[5.09]^{* *}$} & {$[2.92]^{* *}$} & {$[4.98]^{* *}$} & {$[4.83]^{* *}$} & {$[3.82]^{* *}$} \\
\hline \multirow[t]{2}{*}{ Second gen. $(0 / 1)$} & -0.02 & & & -0.02 & & & -0.02 & & \\
\hline & {$[3.45]^{* *}$} & & & {$[3.35]^{* *}$} & & & {$[3.54]^{* *}$} & & \\
\hline \multirow[t]{2}{*}{2.5 Gen-mom foreign $(0 / 1)$} & 0.009 & & & 0.009 & & & 0.009 & & \\
\hline & [1.00] & & & {$[0.98]$} & & & {$[1.01]$} & & \\
\hline \multirow[t]{2}{*}{2.5 Gen-dad foreign $(0 / 1)$} & 0.033 & & & 0.032 & & & 0.033 & & \\
\hline & {$[4.30]^{* *}$} & & & {$[4.19]^{* *}$} & & & {$[4.35]^{* *}$} & & \\
\hline \multirow[t]{2}{*}{ Average volunteering 1989} & 0.126 & 0.111 & 0.398 & 0.149 & 0.132 & 0.411 & 0.138 & 0.121 & 0.365 \\
\hline & 1.41] & {$[1.14]$} & {$[2.86]^{* *}$} & [1.71] & {$[1.40]$} & {$[3.09]^{* *}$} & [1.45] & {$[1.18]$} & {$[2.74]^{* *}$} \\
\hline \multirow[t]{2}{*}{ Inequality measure } & -0.13 & -0.115 & 0.037 & -0.387 & -0.373 & 1.055 & 0.524 & 0.498 & 1.481 \\
\hline & {$[2.14]^{*}$} & [1.94] & {$[0.40]$} & {$[1.58]$} & {$[1.55]$} & {$[2.28]^{*}$} & [0.59] & [0.54] & {$[0.71]$} \\
\hline Observations & 103937 & 91713 & 6353 & 103937 & 91713 & 6353 & 103937 & 91713 & 6353 \\
\hline
\end{tabular}

${ }^{a}$ Coefficients are shown along with absolute values of t-statistics for the eighteen regressions of interest. All regressions use probability weights for sample inclusion and clustering on the highest relevant level for the most conservative standard errors possible in the analysis. All regressions further include controls for year and region as well as the individual and area characteristics enumerated in Table 2. Regressions are stratified by inequality measure, city size status, as well as whether the natives in the sample of interest are the full group, the 3 rd-plus or the second generation of natives. ${ }^{*}$ and ${ }^{* *}$ show statistical significance at the $5 \%$. 
Table 5 Effect of fraction foreign born of your racial group on volunteering ${ }^{a}$

Panel A: All cities

\begin{tabular}{|c|c|c|c|c|c|c|c|c|c|}
\hline & \multicolumn{3}{|c|}{ White } & \multicolumn{3}{|c|}{ Asian } & \multicolumn{3}{|c|}{ Hispanic } \\
\hline & Full sample & $3+$ gen & 2 2nd gen & Full sample & $3+$ gen & 2nd gen & Full sample & $3+$ gen & 2nd gen \\
\hline & [1] & [2] & [3] & [4] & {$[5]$} & [6] & [7] & [8] & [9] \\
\hline \multirow[t]{2}{*}{ Fraction foreign born-your ethnicity } & -4.136 & -4.029 & -8.946 & -9.073 & -15.267 & 3.295 & 0.245 & 0.509 & -0.46 \\
\hline & {$[3.56]^{* *}$} & {$[3.43]^{* *}$} & {$[4.33]^{* *}$} & {$[1.56]$} & [0.82] & {$[0.38]$} & {$[0.47]$} & [0.92] & {$[0.38]$} \\
\hline \multirow[t]{2}{*}{ Second gen. (Binary) } & -0.018 & & & -0.025 & & & -0.018 & & \\
\hline & [1.61] & & & [0.81] & & & {$[2.71]^{* *}$} & & \\
\hline \multirow[t]{2}{*}{2.5 Gen-mom foreign (Binary) } & 0.003 & & & 0.005 & & & 0.019 & & \\
\hline & {$[0.25]$} & & & {$[0.10]$} & & & {$[1.50]$} & & \\
\hline \multirow[t]{2}{*}{2.5 Gen-dad foreign (Binary) } & 0.02 & & & -0.054 & & & 0.043 & & \\
\hline & {$[1.97]^{*}$} & & & {$[0.78]$} & & & {$[4.82]^{* *}$} & & \\
\hline \multirow[t]{2}{*}{ Average volunteering 1989} & 0.21 & 0.202 & 0.268 & 0.677 & 0.665 & 1.279 & 0.289 & 0.431 & 0.055 \\
\hline & {$[2.79]^{* *}$} & {$[2.63]^{* *}$} & [1.41] & {$[2.87]^{* *}$} & {$[1.56]$} & {$[4.56]^{* *}$} & {$[3.79]^{* *}$} & {$[4.81]^{* *}$} & {$[0.40]$} \\
\hline \multirow[t]{2}{*}{ Inequality measure } & -0.023 & -0.01 & -0.011 & 0.499 & 2.019 & 0.32 & 0.155 & 0.293 & 0.357 \\
\hline & {$[0.35]$} & {$[0.15]$} & {$[0.08]$} & {$[1.08]$} & {$[1.80]$} & {$[0.73]$} & {$[1.08]$} & {$[1.84]$} & {$[1.20]$} \\
\hline Observations & 139512 & 129593 & 3516 & 3008 & 1042 & 1481 & 13368 & 8099 & 3285 \\
\hline \multicolumn{10}{|l|}{ Panel B: Large cities } \\
\hline & \multicolumn{3}{|c|}{ White } & \multicolumn{3}{|c|}{ Asian } & \multicolumn{3}{|c|}{ Hispanic } \\
\hline & Full sample & $3+$ gen & 2nd gen & Full sample & $3+$ gen & 2nd gen & Full sample & $3+$ gen & 2nd gen \\
\hline & [1] & [2] & [3] & [4] & [5] & [6] & [7] & [8] & [9] \\
\hline \multirow[t]{2}{*}{ Fraction foreign born-your ethnicity } & -4.475 & -4.402 & -4.114 & -3.487 & -33.827 & 13.182 & 2.798 & 4.585 & 1.011 \\
\hline & {$[2.21]^{*}$} & {$[2.16]^{*}$} & [1.24] & {$[0.16]$} & {$[0.40]$} & [0.53] & {$[4.73]^{* *}$} & {$[6.09]^{* *}$} & {$[0.67]$} \\
\hline \multirow[t]{2}{*}{ Second gen. (Binary) } & -0.027 & & & -0.028 & & & {$[2.18]^{*}$} & & \\
\hline & {$[2.49]^{*}$} & & & [0.82] & & & 0.017 & & \\
\hline
\end{tabular}


Table 5 Effect of fraction foreign born of your racial group on volunteering ${ }^{a}$ (Continued)

\begin{tabular}{|c|c|c|c|c|c|c|c|c|c|}
\hline \multirow[t]{2}{*}{2.5 Gen-mom foreign (Binary) } & 0.003 & & & -0.001 & & & 0.017 & & \\
\hline & {$[0.19]$} & & & {$[0.01]$} & & & [0.99] & & \\
\hline \multirow[t]{2}{*}{2.5 Gen-dad foreign (Binary) } & 0.021 & & & -0.085 & & & 0.045 & & \\
\hline & {$[1.74]$} & & & {$[0.85]$} & & & {$[3.96]^{* *}$} & & \\
\hline \multirow[t]{2}{*}{ Average volunteering 1989} & 0.065 & 0.058 & -0.039 & 0.532 & -0.88 & 1.748 & 0.207 & 0.336 & 0.116 \\
\hline & {$[0.56]$} & {$[0.48]$} & {$[0.15]$} & [1.19] & {$[1.27]$} & {$[4.80]^{* *}$} & {$[1.84]$} & {$[2.51]^{*}$} & {$[0.49]$} \\
\hline \multirow[t]{2}{*}{ Inequality measure } & -0.039 & -0.014 & -0.219 & 0.502 & 4.803 & 0.303 & -0.095 & -0.23 & 1.391 \\
\hline & {$[0.49]$} & {$[0.17]$} & {$[1.45]$} & {$[0.80]$} & {$[0.76]$} & {$[0.52]$} & {$[0.69]$} & {$[1.32]$} & {$[4.08]^{* *}$} \\
\hline Observations & 80021 & 73165 & 2653 & 1485 & 304 & 993 & 8816 & 5144 & 2420 \\
\hline
\end{tabular}

Inequality Measure: Fraction Foreign Born Below Poverty.
${ }^{a}$ Coefficients are shown along with absolute values of t-statistics for the fifty-four regressions of interest (18 in 3 subsections of this table). All regressions use probability weights for sample inclusion and clustering on

the highest relevant level for the most conservative standard errors possible in the analysis. All regressions further include controls for year and region as well as the individual and area characteristics enumerated in

Table 2. Regressions are stratified by inequality measure employed as well as whether the natives in the sample of interest are the full group, the 3rd-plus or the second generation of natives. Further stratification is

on the race of the affected natives (white, Asian, Hispanic). * and ** show statistical significance at the $5 \%$ and the $1 \%$ level respectively. 
Both Panels in Table 2 display a negative relationship between the fraction of foreign born individuals from the 1990-2000 cohort and the likelihood that natives in the sample will volunteer. It is also true that the regressions are not invariant to the choice of individual and area-level controls. Negative impacts of immigration are especially pronounced for the full sample of cities, but less so for the sample of larger cities. This is the first indication that big cities may be different than the full sample in feeling a smaller impact of diversity on individual volunteering, which is consistent with the explanation that the effect seen can be partially attributed to the preferences of residents of cities, as opposed to the negative impact of immigration on native volunteering rates. Within the sample of affected natives, second generation individuals are the least likely to volunteer. This result is maintained with some frequency throughout the analysis. It is also true that, for some specifications, 2.5 generation individuals with a foreign father are the most likely of all natives to volunteer. This is an interesting result, and may indicate that a foreign father makes individuals more tied to communities, while a native mother makes them more able to integrate into the current society in order to volunteer.

Table 3 again splits the regressions into those relating to the full sample (Panel A) and the large city sample (Panel B), and employs all relevant control characteristics, including the selection correction and income inequality measures (as well as year and region dummies) $)^{5}$. Further stratification of regressions is based on which inequality measure is used. Results are shown for the "full" sample of natives (2nd, 2.5 and thirdplus generation) in columns 1,4 , and 7 , as well as for the third-plus generation in columns 2, 5, and 8, and for the second generation in columns 3, 6 and 9 .

Turning first to Panel A, I find that, regardless of the inequality measure used, immigrants have a negative impact on the likelihood of natives volunteering. It is also true that the average volunteering in 1989 is positively related to current levels of volunteering. Once again, foreign born fathers and native mothers have children who volunteer more, while the negative impact of the second generation is not quite statistically significant at the $10 \%$, but only at the $5 \%$ level. These results look very similar to those in Table 2 and appear to show a strong effect of immigration. Interestingly, there is little impact of any of the inequality measures. The robustness check using a smaller set of area characteristics still showed a similar pattern of results with a smaller (but still significant at the 5\% level) effect of immigration and a larger effect of some measures of inequality.

In large cities examined in Panel B, in keeping with results in Table 2, the pattern of effects is not as clear. Although the second generation is negatively impacted by the volunteering of immigrants, there is no measurably significant impact on the third-plus generation, which is arguably more important for the present analysis. This provides further evidence that large cities are not being negatively impacted by the effect of immigration on the provision of public goods, and may mitigate the relative importance of immigrants in decreasing social cohesion more generally. It is also notable that previous volunteering and inequality did not seem to matter much in these large cities, while in the larger sample of cities, average 1989 volunteering still had a measurable impact.

The next possibility I explored was that the effect of immigration varied by type of immigrant, and furthermore, that immigrants were impacting others of their own ethnicity more strongly than natives in other ethnic groups. Tables 4 and 5 examine 
the effects of race and ethnicity for Asian, Hispanic and white immigrants-with Black immigrants excluded due to their small numbers in this cohort. Table 4 first examines the impact of immigration by race on all types of native individuals, while Table 5 examines the impact of immigration of individuals of one's own-race (i.e. Asian immigrants on Asian natives) ${ }^{6}$. Specifically, Table 5 uses three entirely different samples of natives (i.e. those of White, Asian or Hispanic race) and examines specifically the effect of immigration of individuals of the same ethnicity as the natives in each of the three race/ethnic groups of interest. Both tables use the panel structure for city size breakout, as well as separately looking at different measures of inequality and generation of natives.

In Table 4, both panels show a relationship with volunteering which is positive for Asian immigration and negative for white immigration. This result is generally consistent-with the positive relationship with Asian immigration reduced in significance below traditional levels (5\% or 10\%) for the second generation of natives. While Hispanic immigration has a negative relationship for the full sample of cities, this effect is not significant at statistical levels in the group of larger cities. This difference in the Hispanic relationship in particular could explain the varying effect of immigration on native volunteering in large versus small cities.

Next, the hypothesis that immigration by race has an effect because individuals interact to a greater extent with others of their own race was explored. The layout of Table 5 has the same panel structure as Table 4, with the additional breakout of racial group of interest. The inequality measure here is mean to median income, with other inequality results looking extremely similar and included in Additional file 1: Table S5 for reference. Looking first at white individuals, it is clear that white immigrants have a negative relationship with the volunteering of white natives, thus same-ethnic relationships are quite strong. This is true for all inequality measures and both samples-with some differences in coefficients and significance but the same general pattern of results. For Asian immigrants, relationships are still positive, although significance decreases below the $5 \%$ level in most cases, so it is difficult to draw consistent conclusions. It would appear, however, that Asian immigration is not having a detrimental impact on Asian natives.

There is very little significance in the relationship between Hispanic immigrants and Hispanic native volunteering in the full sample of cities. However, the impact of Hispanic immigrants on Hispanic native volunteering is actually positive in large cities. This could explain why there was no negative impact of Hispanic immigrants in large cities in Table 3. Namely, any negative impact is counterbalanced by the positive same-ethnic effects.

In summary, my results so far lend support to the idea that immigration negatively affects volunteering rates in the full sample of cities, with the caveat that these results are generally not maintained in the large-and densely populated-cities. My results may be explained by the positive interactions that Hispanic immigrants enjoy with Hispanic natives in large cities, perhaps because of enclaves, making the negative impact at the larger city-group level disappear. Considering that the 19902000 cohort was largely composed of Hispanic immigrants, this difference may explain the anomalous nature of United States social cohesion erosion.

The results may also be influenced by native selection on individualism. 
It is also true that while white immigrants may have a negative impact (both generally and at an own-ethnic level), while Asian immigrants appear to have a positive effect on volunteering rates. One possibility for the existence of this posited large negative impact of white immigrants on white individuals is the concept of social threat.

Specifically, social threat theory maintains that natives are happy to help immigrants until the point that they threaten their own identity. An immigrant who looks similar to a native poses a larger "threat" than one who looks dissimilar and may have a harder time competing. In the "white" community, this concept of protecting one's identity from the success of immigrants of one's own type may, in fact, be a more relevant concern than in minority populations.

\section{Auxiliary analyses}

Country of Origin-Additional file 1: Table S1 explores the possibility that country of origin, rather than ethnicity, is the responsible agent. In line with previous results, this table appears to show a positive effect of immigrants from Asia on volunteering in the full sample of cities. The full sample of cities also appears to show negative effects of Caribbean, European and "possibly" Mexican immigrants. The results for Europeans would then be in accordance with the possibility derived from Tables 4 and 5 that white immigrants have a negative impact on volunteering.

In large cities, however, the effects are less consistently significant-this is in line with weaker effects of immigration in large cities as discussed in previous tables. Although being born in Africa or South America may have a "positive impact", with the South America results perhaps similar to the positive effect of Hispanics in large cities, these results are not consistently significant. There are also inconsistent negative effects of being from Oceania, South America and Mexico. Overall, the effects for the large city regressions are less significant, and do not appear to show as much of an effect of immigration as those for the full sample. This is in line with expectations given the results in earlier tables in this analysis.

Type of volunteering-I next explored differences in the effects of immigration on various types of volunteering, with the particular categories of interest being religious, civic, social services, immigrant-focused, international, and volunteering for a child-focused organization. This is important since one might argue that volunteering for a children's organization, as an example, is at least a partially self-interested act by a parent and not necessarily representative of more general forms of volunteering. See Neymotin (2013) for a discussion of the link between parental involvement in schooling and child behavioral outcomes. Results are generally similar for all of these different types. This point is very interesting since it means that, at least in this fashion, immigration is affecting education through involvement in exactly the same way as it affects other forms of social cohesion, making it possible to further generalize results.

In Additional file 1: Table S2, regressions are shown for six different types of volunteering (kids, religious, civic, social services, international and immigrantfocused), and regressions were run for the full set of natives, as well as the subset of the third-plus generation. Results were also run for both an overall measure of immigration as well as a measure using the fraction from different racial groups.

All regressions used the ratio of average to median income as the relevant measure of inequality. Regressions using other inequality measures provided similar results. 
The various types of volunteering are found to be different in their relationship to immigration. While there may be differences in magnitude or significance, however, there does not seem to be any change in sign for these coefficients. For instance, white immigrants do appear to have a negative impact on volunteering, although this effect is clearly insignificant when it comes to volunteering for an immigrant group. Similarly, Asian immigrants have a positive impact, although the strength of the effect is strongest for the religious and the international regressions. Being born Hispanic, interestingly, has a negative impact, but it is only significant at conventional levels for religious and civic volunteering. Taken as a larger measure, volunteering for immigrant groups does not seem to be too closely related to immigrant representation. The reasoning here might be that immigrants normally have a negative impact on immigration, but for this particular type of immigration it should be positive, leading to a zero net effect. Overall, these results mirror those from the main analysis for the full sample of cities.

Linear probability model-The next specification employed was the linear probability model for an individual's decision to volunteer. The coefficient on the average 1989 volunteering in the community was, alternatively, (a) unrestricted, (b) $=1$, and (c) $=0.5$. Additional file 1: Table S3 examines the results of using these three additional specifications, and is similar in structure to Table 3. However, only the full sample of cities is employed in this table, with (undisplayed) results from stratifying on city size or using a smaller set of city characteristics providing similar results for the purposes of this robustness check.

Additional file 1: Table S3 shows that, for all specifications of interest, the probit model provides similar results to those coming from the linearized regression models. The "differenced" regression, i.e. (b) $=1$, does have slightly lower levels of significance on the effect of the fraction foreign born. Even so, the effect on the $3^{+}$ generation is still always significant at the $10 \%$, if not always at the $5 \%$ level.

It is also true that using the linearized regression shows stronger impacts of the inequality measures in several cases, indicating that there may indeed have been some noise arising from using the smaller 1989 CPS supplement. Overall, the linearized regressions provide further support in keeping with the negative relationship between the fraction foreign born in the city and social cohesion. This effect appears relatively consistent throughout the various instantiations employed. Linearized regressions (results not shown) were also run using a structure similar to Table 4 (by race) and Table 5 (own-race) with a similar pattern of effects to those in Additional file 1: Table S3. Namely, while results in the linearized regressions generally mirrored those in the probit regressions, the "difference" regression had the weakest effects-although, with the exception of white own-race effects, they were still significant at the $10 \%$ level if they had been significant at the $5 \%$ or the $1 \%$ in the probit structure. Overall, results were seen to verify patterns in the main portion of the analysis.

Voting-The final auxiliary analysis employed whether an individual voted, rather than volunteered, as the measure of social cohesion. Additional file 1: Table S4 displays the results from this final specification and uses a table layout equivalent to that used in Table 3. Voting is negatively related to the fraction of immigrants in an area, and, in contrast to results for volunteering, this effect does not diminish when 
focusing on larger cities. If anything, the effect of immigration on voting tends to be magnified in size in larger cities. Regressions employing a race and own-race structure found similar results, with larger cities showing the same or larger impacts of immigration on the likelihood of an individual voting. In contrast to volunteering, own-race differences with Hispanic enclaves do not appear to tell the story for voting. This is expected, since larger city effects do not diminish relative to the entire sample. Results are available upon request.

These preliminary results on voting verify its negative relationship with immigrant representation. However, these results do not implicate city size in the same way as in the regressions with volunteering as the measure of social cohesion. The reason could be due to the interactive nature of volunteering, in contrast to voting, which occurs as a solitary act, so that city size will function differently.

\section{Conclusions}

Since Putnam's 2007 work showing that immigration decreased social cohesion in towns in Italy, scholars have been trying to replicate and verify results for the United States, as well as for Europe, with limited success. Difficulty in finding appropriate data, as well as methods to control for selection and income inequality have hampered their efforts at answering this question.

My paper is innovative in presenting one plausible explanation for why Europe and the United States have such different effects of immigration on social cohesion as measured by the traditional "club associations/volunteering," while attempting to address the previously mentioned concerns.

Although some prior works did stratify results by city size, they found little verifiable empirical results (Alesina et al. 1999). Examining the outcome of volunteering, it appears that the problem has been a decrease in social cohesion in the smaller (or rather, "less large") cities in the United States with a particular problem with Hispanic immigrants-as compared to larger cities. Thus, large city data do appear similar to European results in showing a lack of a relationship between immigration and volunteering after accounting for income inequality. It is the smaller U.S. cities, admittedly dissimilar from Europe in culture and contact with other groups, which look anomalous in this immigration-social cohesion relationship, since immigration still does have an effect after controlling for inequality measures. This being said, it is not possible to dismiss the possibility mentioned earlier that natives selectively move to larger or smaller cities conditional on their individuality. This hypothesis is supported by the large-city size results.

Although there has been some preliminary work on the effects of immigration on social cohesion in homogeneous societies (Yamamura 2008), this is not an area that has been particularly well-explored or understood. For this reason, the United States still tends to look anomalous and my analysis is unique in exploring this genre of effects at all.

In the case of voting, however, it is true that while immigration is negatively related to social cohesion, preliminary analyses here indicate that the pathway by which immigrants are assimilated, and the type of social cohesion built may look somewhat dissimilar relative to city size relationships for volunteering. For this reason, employing two different measures of social cohesion is also useful in beginning to understand the exact method in which immigrants are assimilated into society. 
Moving forward, if we would like to continue to increase social cohesion in order to gain benefits to society, and if it is truly smaller cities that have difficulty assimilating immigrants, then the focus needs to be on assimilating the particular groups of Hispanic immigrants in smaller cities and, to a lesser extent because they are a smaller section of the population, white immigrants. This would fly in the face of new programs, which tend to target larger cities. It is also true that a positive effect of Asian immigration can be taken from these results, so that this particular subgroup would not be seen as inherently detrimental to the well-being and functioning of native social cohesion in the United States.

One possible direction for future research is to identify the existence of a tipping point in city size wherein the relationship between immigration and volunteering measures of social cohesion begins to change from smaller cities, that experience a decrease in social cohesion with increasing Hispanic immigration, to larger cities where this no longer seems to be an issue, and Hispanic immigrants may even increase social cohesion with, in particular, their fellow Hispanics. This tipping point hypothesis is in keeping with a suggestion by Robert Putnam in his 2007 work, which he could not quite find evidence for in that particular data. On a similar note, it would be useful to extend the present voting results to employ smaller levels of aggregation, such as census local areas or tract data on voting and communities, to determine the effect of smaller or larger areas in this context.

It should also be noted that there are alternative explanations for these results. One possibility is that other individual characteristics in the data are biasing the effect of immigration. This was a choice of specification made so that the analysis was not hampered by omitted variables bias from the deletion of key individual characteristics from the analysis. Slight variations in the inclusion of individual factors did not, however, change the essential nature of the results.

Chief among the more plausible explanations are that, rather than an inability of small cities to assimilate immigrants in the volunteering data, there is either (a) selective response on Hispanic ethnicity conditional on city size and, therefore, comfort in being identified as a member of this group, or (b) a different type of Hispanic immigration proceeding into larger versus smaller cities, with the possibility that legal versus illegal immigrants show up differently by city size in this data, and (c) the previously mentioned possibility that natives sort on city size conditional on individualism.

The first explanation will, undoubtedly, be a factor which is quite difficult to discount. As for the second effect, it has been addressed to some extent by controlling for selection on observable average historic volunteering levels. However, it is possible that facets of Hispanic immigration which differ between the locations still remain intact, and this is indeed a factor at play. It is also telling that, for voting, the city size and Hispanic element does not seem to come into play in the same respect. This points to a clear need to consider the type of social cohesion carefully when examining the reasons for the accrual of social cohesion within communities. Finally, the third point has been extensively discussed as a plausible alternative, noting of course that natives generally in the literature do not sort between areas larger than the county level (and often the literature also shows lack of sorting between different MSA's).

It is also true that the results from various types of volunteer organizations can provide further guidance on where exactly social cohesion may be breaking down. The 
relationships discovered were not limited to religious or child-focused organizations, but also appeared for civic, international and perhaps social services organizations. This implies that individuals are not simply following patterns driven by clergy and other religious leaders, nor are they volunteering to help their own children based on these immigration patterns. The results gathered for these various different types of volunteering organizations indicate that the patterns for relationships documented are more generally applicable irrespective of the types of volunteering involved.

Taken together, the present analysis has made large inroads in an effort to clear up a fledgling debate in the literature and helps contribute to our understanding of exactly how social cohesion may be affected by an influx of immigrants to the United States, and thereby possibly affect other important aspects of society.

In the case of volunteering, it appears to be occurring through the smaller cities for the most part, while larger cities have results more similar to those in Europe. In these small cities, it also appears to be white and Hispanic immigrants who are of interest in the relationship, with an inability of smaller communities to easily assimilate Hispanic immigrants perhaps being the reason for this documented relationship.

\section{Endnotes}

${ }^{1}$ Hours of volunteering were available but not employed due to (a) evidence that, without a two-part hurdle structure-unavailable in this data-hours will be incorrectly measured (Hamermesh and Trejo 2013), (b) the difficulty in accurately measuring hours of volunteering due to recall bias in individuals remembering exact hours volunteered - rather than a simple binary indicator for participation-from the previous year, (c) evidence that the extensive rather than the intensive margin is the relationship of interest here, also in keeping with evidence in Letki (2008) that the social trust does not relate to the intensive margin of volunteering behaviors.

${ }^{2}$ It is also true that natives may sort by area even at these higher levels of aggregation, and the effect of this sorting is later discussed in moderating the strength of results in this analysis.

${ }^{3}$ While Hispanic race was not explicitly included in the measures of the percentage representation by race in the Census data used, there is an unmistakably strong correlation between Hispanic and "other race." The current analysis, while including a binary for Hispanic at the individual level, does not separately control for the percentage "other race." Results were repeated including a control for the percentage other-race and found only very small differences in magnitude and almost never moved any coefficients of interest from statistically significant at the $5 \%$ or $1 \%$ level to lower levels of insignificance.

${ }^{4}$ Notice that the nature of the regression structure, in particular probability weighting for sample inclusion, precluded an analysis with fixed effects for location choice in this case.

${ }^{5}$ Prior to this paper version, regressions were stratified by region with the notable result that effects were generally concentrated in the Western region of the United States. Current regressions focus on the more aggregated version of the paper to retain the largest dataset possible.

${ }^{6}$ Alternatively, regressions using all breakdowns of immigration by ethnicity on affecting natives of each separate race were run, however, there was insufficient data size to 
include this in the present analysis. One point which was clear, however, was that results were quite strong for white natives, with Hispanic natives negatively affected by white immigrants only in the larger cities. Results for Asians generally employed very small datasets-less than 1000 in many cases-so that they had even less predictive power than the Hispanic-native regressions.

\section{Additional file}

Additional file 1: Table S1. Effect of Immigration by Country of Origin on Volunteering. Table S2. Effect of Fraction Foreign Born on Volunteering by Type. Table S3. Effect of Foreign Born on Volunteering. Table S4. Effect of Fraction Foreign Born on Voting. Table S5. Effect of Fraction Foreign Born of Your Racial Group on Volunteering.

\section{Competing interests}

The IZA Journal of Migration is committed to the IZA Guiding Principles of Research Integrity. The author declares that she has observed these principles.

\section{Acknowledgements}

I would like to thank David Card, Joni Hersch, Dennis Weisman and an anonymous referee for helpful comments and suggestions. Outstanding research assistance was provided by Andrew Wagner, Yunyun Lv and Brian Mulcahey. All mistakes are my own.

Responsible editor: Amelie F Constant.

Received: 15 November 2013 Accepted: 3 March 2014

Published: 24 March 2014

\section{References}

Alesina A, Baqir R, Easterly W (1999) Public goods and ethnic divisions. Q J Econ 114(4):1243-1284

Alesina A, La Ferrara E (2005) Ethnic diversity and economic performance. J Public Econ 43(3):762-800

Alesina A, La Ferrara E (2002) Who trusts others? J Public Econ 85:207-234

Bartel AP (1989) Where do the new U.S. immigrants live? J Labor Econ 7:371-391

Becares L, Stafford M, Laurence J, Nazroo J (2011) Composition, concentration and deprivation: exploring their association with social cohesion among different ethnic groups in the UK. J Urban Stud 48(13):2771-2787

Card D (2001) Immigrant inflows, native outflows, and the local labor market impacts of higher immigration. J Labor Econ 19(1):22-63

Card D, DiNardo JE, Estes E (2000) The More Things Change: Immigrants and the Children of Immigrants in the 1940s, the 1970s, and the 1990s. In: Borjas GJ (ed) Issues in the Economics of Immigration. University of Chicago Press, Chicago, pp 227-270

Costa DL, Kahn ME (2003) Civic engagement and community heterogeneity: an economist's perspective. Perspect Polit 1(1):103-111

Demireva N (2011) Briefing: Immigration, Diversity and Social Cohesion. The Migration Observatory at the University of Oxford, pp 1-6

Dustmann C, Fabbri F, Preston I (2005) The impact of immigration on the British labour market. Econ J 115(507):F324-F341

Easterly W, Levine R (1997) Africa's growth tragedy: policies and ethnic divisions. Q J Econ 112(4):1203-1250

Friedberg RM, Jaeger DA (2009) The Economic Diversity of Immigration across the United States. IZA Discussion Paper 4555

Galabuzi GE, Teelucksingh C (2010) Social Cohesion, Social Exclusion, Social Capital. Region of Peel Immigration Discussion Paper

Gele AA, Harslof I (2012) Barriers and facilitators to civic engagement among elderly African immigrants in Oslo. J Immigr Minor Health 14(1):166-174

Gesthuizen M, Van Der Meer T, Scheepers P (2009) Ethnic diversity and social capital in Europe: tests of Putnam's thesis in European countries. Scand Pol Stud 32(2):121-142

Glaeser EL, Laibson DI, Scheinkman JA, Soutter CL (2000) Measuring trust. Q J Econ 115(3):811-846

Gorney A, Torunczyk-Ruiz S (2011) Integration of migrants from the perspective of social ties and neighbor relations. CMR Working Paper 48/106

Green A, Janmaat G, Cheng H (2011) Social cohesion: converging and diverging trends. Natl Inst Econ Rev 215:R6-R22 Gustavsson M, Jordahl H (2006) Inequality and Trust in Sweden: Some Inequalities are More Harmful than others. IFN Working Paper 673

Hamermesh DS, Trejo SJ (2013) How do immigrants spend their time? The process of assimilation. J Popul Econ 26(2):507-530

Handy F, Greenspan I (2009) Immigrant volunteering: a stepping stone to integration? Nonprofit Volunt Sect Q 38(6):956-982

Holtug N (2010) Immigration and the politics of social cohesion. Ethnicities 10(4):435-451

Hooghe M, Reeskens T, Stolle D, Trappers A (2009) Ethnic diversity and generalized trust in Europe: a cross-national multilevel study. Comp Pol Stud 42:198-223

Kesler C, Bloemraad I (2010) Does immigration erode social capital? The conditional effects of immigration-generated diversity on trust, membership and participation across 19 countries 1981-2000. Can J Pol Sci 43(2):319-347 
Letki N (2008) Does diversity erode social cohesion? Social capital and race in British neighborhoods. Pol Stud 56:99-126

Mohan J, Twigg L, Taylor J (2011) Mind the double gap. Br J Criminol 51:1035-1053

Neymotin F (2009) Immigration and its effect on the college-going outcomes of natives. Econ Educ Rev 28(5):538-550

Neymotin F (2013) How parental involvement affects childhood behavioral outcomes, forthcoming in journal of family and economic issues.

Poterba JM (1997) Demographic structure and the political economy of public education. J Pol Anal Manage 16(1):48-66

Putnam RD (2007) E Pluribus Unum: diversity and community in the twenty-first century: the 2006 Johan Skytte prize lecture. Scand Pol Stud 30(2):137-174

Ramazzotti P (2010) Industrial districts, social cohesion and economic decline in Italy. Camb J Econ 34:955-974

Simpson L (2006) Ghettos of the Mind: The Empirical Behaviour of Indices of Segregation and Diversity. CCSR Working Paper 2006-06

Tong $Y$ (2010) Foreign-born concentration and acculturation to volunteering among immigrant youth. Soc Force 89(1):117-143

Vigdor $J \mathrm{~L}$ (2004) Community composition and collective action: analyzing initial mail response to the 2000 census. Rev Econ Stat 86(1):303-312

Yamamura E (2008) Determinants of trust in a racially homogeneous society. Econ Bull 26(1):1-9

doi:10.1186/2193-9039-3-5

Cite this article as: Neymotin: Immigrant influx and social cohesion erosion. IZA Journal of Migration 2014 3:5.

Submit your manuscript to a SpringerOpen ${ }^{\circ}$ journal and benefit from:

- Convenient online submission

- Rigorous peer review

- Immediate publication on acceptance

- Open access: articles freely available online

- High visibility within the field

- Retaining the copyright to your article

Submit your next manuscript at $\gg$ springeropen.com 